\title{
(W Virology, epidemiology, pathogenesis, and control of enterovirus 71
}

\author{
Tom Solomon, Penny Lewthwaite, David Perera, Mary Jane Cardosa, Peter McMinn, Mong How Ooi
}

Lancet Infect Dis 2010; 10: 778-90

Published Online October 18, 2010 DOI:10.1016/S14733099(10)70194-8

Brain Infections Group, Institute of Infection and Global Health

ProfT Solomon FRCP,

P Lewthwaite MRCP

$M \mathrm{H}$ Ooi MR(P), and Department of Neuroscience

(ProfT Solomon, M H Ooi), University of Liverpool, Liverpool, UK; Walton Centre

NHS Foundation Trust, Liverpool, UK (Prof T Solomon);

Institute of Health and

Community Medicine, University Malaysia Sarawak,

Sarawak, Malaysia (D Perera PhD,

Prof M J Cardosa DPhil); Department of Paediatrics, Sibu Hospital, Sibu, Sarawak, Malaysia (M H Ooi); and Royal Prince Alfred Hospital, University of Sydney, NSW, Australia

(Prof P McMinn FRCPath)

Correspondence to:

ProfTom Solomon, Brain Infections Group, Institute of Infection and Global Health, University of Liverpool, Duncan

Building, Daulby Street,

Liverpool L69 3GA, UK

tsolomon@liverpool.ac.uk

For the revised classification see http://www.picornaviridae. com/enterovirus/enterovirus. htm

First isolated in California, USA, in 1969, enterovirus 71 (EV71) is a major public health issue across the Asia-Pacific region and beyond. The virus, which is closely related to polioviruses, mostly affects children and causes hand, foot, and mouth disease with neurological and systemic complications. Specific receptors for this virus are found on white blood cells, cells in the respiratory and gastrointestinal tract, and dendritic cells. Being an RNA virus, EV71 lacks a proofreading mechanism and is evolving rapidly, with new outbreaks occurring across Asia in regular cycles, and virus gene subgroups seem to differ in clinical epidemiological properties. The pathogenesis of the severe cardiopulmonary manifestations and the relative contributions of neurogenic pulmonary oedema, cardiac dysfunction, increased vascular permeability, and cytokine storm are controversial. Public health interventions to control outbreaks involve social distancing measures, but their effectiveness has not been fully assessed. Vaccines being developed include inactivated whole-virus, live attenuated, subviral particle, and DNA vaccines.

\section{Introduction}

Enteroviruses are small, single-stranded, positive-sense RNA viruses from the enterovirus genus in the family Picornaviridae. ${ }^{1}$ They cause disorders with a wide range of clinical manifestations, including cutaneous, visceral, and neurological diseases. For many years polioviruses were the most important enteroviruses, since they led to large outbreaks of paralytic disease. A global campaign has, however, almost eradicated poliomyelitis from many regions worldwide. In its place, enterovirus 71 (EV71) causes major outbreaks of hand, foot, and mouth disease (HFMD), most frequently affecting children. This virus was first described in $1969,{ }^{2}$ although an analysis shows that EV71 was circulating in the Netherlands as early as 1963. ${ }^{3}$ Although present in most countries, the largest outbreaks of disease have been seen in the Asia-Pacific region, for reasons that are incompletely understood. ${ }^{4-16}$ The neurological manifestations range from aseptic meningitis to acute flaccid paralysis and brainstem encephalitis, which is associated with systemic features, such as severe pulmonary oedema and shock, in many cases..$^{17,18}$ The clinical features, investigations, and management of severe EV71 disease are discussed in a companion article in The Lancet Neurology. ${ }^{19}$ In this Review we consider the virology, clinical and molecular epidemiology, pathogenesis, and prospects for control.

\section{Virology \\ Classification}

As well as the enterovirus genus, the large Picornaviridae family includes Rhinovirus spp (eg, the common cold), Hepatovirus spp (eg, human hepatitis A virus), Parechovirus spp (eg, human parechovirus 1 and 2), and two important animal virus genera, Cardiovirus spp (eg, encephalomyocarditis virus) and Aphthovirus spp (foot and mouth disease virus). ${ }^{1}$ Human enteroviruses were traditionally separated into four classifications, according to their pathogenicity in human beings and experimental animals and their cytopathic effects in tissue culture; these subgroups were polioviruses (three serotypes), coxsackievirus A (23 serotypes), coxsackievirus B (six serotypes), and echoviruses (28 serotypes). ${ }^{1}$ However, because of the limitations of this system, serologically distinct human enteroviruses isolated since 1970 have been designated by serotype numbers, beginning with HEV68. The original classification of human enteroviruses has been substituted by a taxonomic scheme based on molecular and biological properties of the viruses. ${ }^{20}$ This revised classification recognises at least 90 subtypes and separates them into four species (table 1). Polioviruses have been designated as members of the human enterovirus $\mathrm{C}$ species because they are genetically closely related. ${ }^{21}$

\section{Physicochemical properties}

The virus capsid comprises 60 identical subunits (protomers), each of which contains a copy of the four structural viral proteins (figure 1). ${ }^{22}$ The lack of a lipid envelope confers human enteroviruses stability in the host environment, including on exposure to human gastric acid, and they can survive at room temperature for several days. EV71 and other enteroviruses have also been detected in surface and ground water and in hot spas. ${ }^{23,24}$ Enteroviruses are resistant to organic solvents (eg, ether and chloroform), alcohol, and freezing, but can be inactivated by temperatures higher than $56^{\circ} \mathrm{C}$, chlorination, formaldehyde, and ultraviolet irradiation. In one study EV71 was destroyed by virucidal disinfectants. ${ }^{25}$

\section{Life cycle and replication}

Human beings are the only known natural hosts of human enteroviruses. Like most other enteroviruses the replication cycle of EV71 is similar to that of polioviruses. ${ }^{26}$ Viral entry into susceptible host cells is dependent on specific receptors. Seven receptors for different enteroviruses have been identified in human beings. ${ }^{20}$ The specific receptors include the poliovirus receptor (CD155), three integrins ( $\alpha 2 \beta 1, \alpha v \beta 3$, and $\alpha v \beta 6)$, decayaccelerating factor (CD55), the coxsackievirus-adenovirus 


\begin{tabular}{|l|l|}
\hline \multicolumn{2}{|c|}{ Serotype } \\
\hline A & CV-A2-8, CV-A10, CV-A12, CV-A14, CV-A16, EV71, EV76, EV89-92 \\
B & CV-A9, CV-B1-6, E1-7, E9, E11-21, E24-27, E29-33, EV69, EV73, EV74-75, EV77-88, EV93, EV97, EV98, EV100, EV101, EV106, EV107 \\
C & CV-A1, CV-A11, CV-A13, CV-A17, CV-A19-A22, CV-A24, EV95, EV96, EV99, EV102, EV104, EV105, EV109, PV1-3 \\
D & EV68, EV70, EV94 \\
The Picornaviridae Study Group and the International Committee on Taxonomy of Viruses classified the Enterovirus genus into ten species, which include four human \\
enterovirus species (A-D), three human rhinovirus species (A-C), bovine enterovirus, simian enterovirus A, and porcine enteroviruses (http://www.ncbi.nlm.nih.gov/ICTVdb/ \\
ICTVdB/). CV-A=coxsackievirus A. CV-B=coxsackievirus B. EV=enterovirus. E=echovirus. PV=poliovirus. \\
\hline \\
Table 1: Human enterovirus serotypes, by species
\end{tabular}

receptor, and intracellular adhesion molecule 1. Some enteroviruses use more than one receptor to infect a host cell. Several receptors for EV71 have been identified, but a ubiquitously expressed cellular receptor, scavenger receptor B2, and a functional receptor, human P-selectin glycoprotein ligand-1, found on white blood cells, are specific for EV71. ${ }^{27,28}$ Sialic-acid-linked glycan, which is expressed in abundance in the respiratory and gastrointestinal tracts, and dendritic-cell-specific intercellular adhesion-molecule-3-grabbing non-integrin (CD209), which is found exclusively in dendritic cells in lymphoid tissues, have also been identified. ${ }^{29-31}$

After an enterovirus binds with a specific receptor on the cell surface, a series of structural changes occur in the virus capsid (yet to be defined in EV71) and pores are formed in the cell membrane through which the virion RNA is released into the host cell cytoplasm. Being positive-sensed, the parent virus RNA acts directly as a messenger RNA and is translated into a large polypeptide that is promptly cleaved by the viral proteases into 11 mature structural and non-structural proteins. The replication of the virus genome by the error-prone RNA-dependent RNA polymerase 3Dpol takes place in a vesicle membrane structure (viral replication complex). The polymerase is estimated to misincorporate one or two bases in every genome copying event, which explains why the virus mutates and evolves rapidly. Within the VP1 gene $4 \cdot 2-4 \cdot 6 \times 10^{-3}$ nucleotide substitutions occur per site per year, which is similar to the number in poliovirus and greater than that of influenza viruses. ${ }^{32-34}$

While the machinery of the host cellular protein synthesis is shut down by viral protease $2 \mathrm{~A}$, viral protein synthesis remains unaffected. An infectious virus particle is formed after the packaging of a progeny viral RNA into a virus capsid in the cytoplasm of the infected cells. Mature infectious virus particles are released when an infected cell is lysed.

\section{Clinical epidemiology \\ Initial identification}

EV71 was isolated from the stool of a child aged 9 months with encephalitis, in California, USA, in $1969,{ }^{2}$ although an earlier isolate has since been identified. ${ }^{3}$ Within 5 years small outbreaks of neurological infections, including encephalitis and aseptic meningitis, attributed to EV71 were reported in Australia, Japan, Sweden, and the USA. ${ }^{35-39}$

The dermotrophic properties of EV71 were first recognised when the virus caused epidemics of HFMD in Japan in $1973 .{ }^{38,39}$ In the 1970 s, two large EV71 epidemics occurred in Europe. The first, in Bulgaria, was initially attributed to polioviruses because of the epidemiological, clinical, and pathological characteristics. ${ }^{40,41}$ EV71, confirmed by virus isolation or neutralisation test, was later identified as the causative agent in 347 (77\%) of 451 children who presented with non-specific febrile illness or neurological disease; 44 children died. The second major epidemic was 3 years later in Hungary, with 1550 cases (826 aseptic meningitis, 724 encephalitis) and 47 deaths reported; unlike the Bulgarian epidemic, few patients had HFMD. ${ }^{42}$

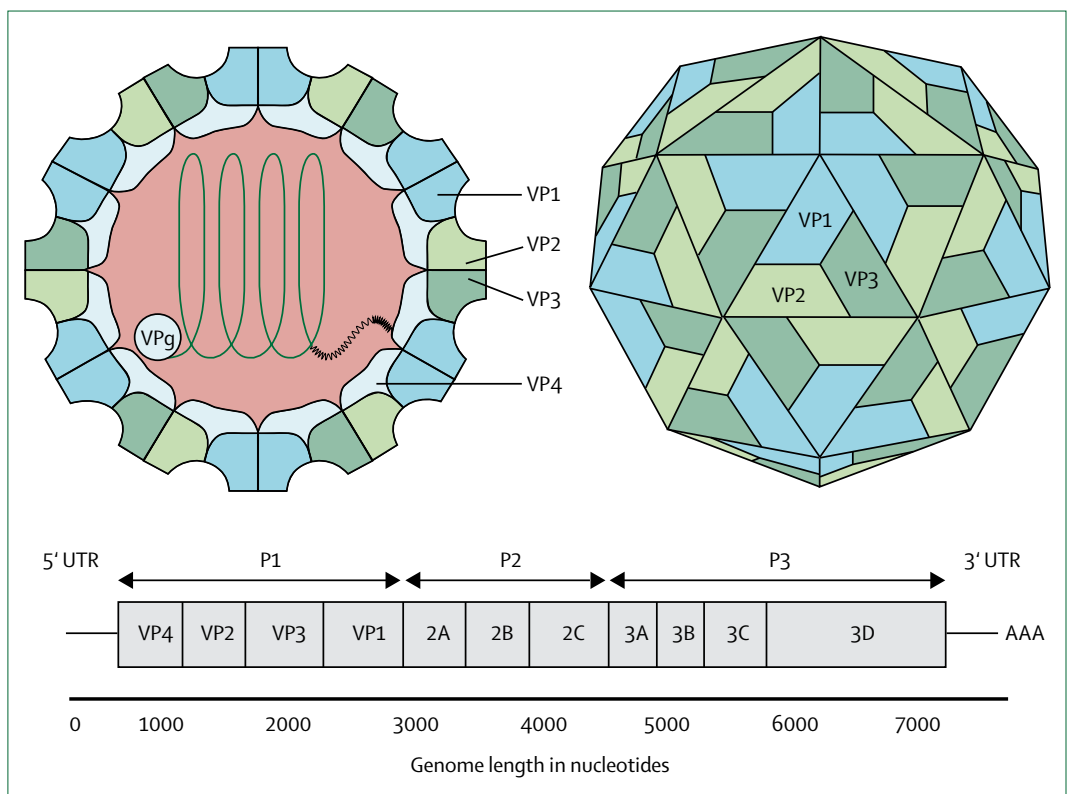

Figure 1: Enterovirus 71 structure and genome structure of the virion

Human enteroviruses are small (circumference around $30 \mathrm{~nm}$ ), non-enveloped, icosahedral particles that contain a single-stranded, positive-sense, polyadenylated virus RNA of approximately $7.4 \mathrm{~kb}$. Each protomer in the virus capsid contains a copy of the four structural viral proteins (VP1-VP4), of which VP1, VP2, and VP3 are external, whereas VP4 is completely internalised and is not, therefore, exposed to the host antibody response. All the structural proteins are encoded by the $\mathrm{P} 1$ region of the genome. The $\mathrm{P} 2$ and $\mathrm{P} 3$ regions encode seven non-structural proteins-2A-2C and 3A-3D. Reproduced from ViralZone, with permission of Swiss Institute of Bioinformatics, and from reference 70 , with permission of Springer. UTR=untranslated region. $\mathrm{VPg}=\mathrm{virus}$ encoded protein. 


\begin{tabular}{|c|c|c|c|c|c|c|c|c|c|c|c|c|c|c|c|c|c|c|}
\hline & 1973 & 1980 & 1986 & 1990 & 1993 & 1994 & 1997 & 1998 & 1999 & 2000 & 2001 & 2002 & 2003 & 2004 & 2005 & 2006 & 2007 & 2008 \\
\hline Singapore & .. & .. & .. & .. & .. & .. & B3, B4 & $\mathrm{B} 3, \mathrm{C} 1$ & B3 & B4* & B4 & $\mathrm{C} 1, \mathrm{~B} 4$ & B4 & - & - & B5 & - & B5 \\
\hline $\begin{array}{l}\text { Peninsular } \\
\text { Malaysia }\end{array}$ & .. & .. & .. & .. & .. & .. & $\begin{array}{l}\mathrm{B} 3^{*}, \mathrm{~B}^{*} \\
\mathrm{C} 1 \dagger, \mathrm{C} 2 \dagger\end{array}$ & $\mathrm{C} 1$ & $\mathrm{~B} 4, \mathrm{C} 1$ & $\begin{array}{l}\mathrm{B} 4^{*}, \\
\mathrm{C}^{*}\end{array}$ & - & - & - & - & $\mathrm{B}^{*}, \mathrm{C} 1$ & - & - & - \\
\hline $\begin{array}{l}\text { Sarawak, } \\
\text { Malaysia }\end{array}$ & .. & .. & .. & .. & .. & .. & $\mathrm{B}^{*}$ & $\mathrm{C} 1$ & None‡ & $\begin{array}{l}\text { B4*, } \\
\text { C1 }\end{array}$ & None $\ddagger$ & $\mathrm{C} 1$ & B5, C1 & None $\neq$ & B5 & B5 & & \\
\hline $\begin{array}{l}\text { Perth, } \\
\text { Australia }\end{array}$ & .. & .. & .. & .. & .. & .. & .. & .. & $\mathrm{B} 3, \mathrm{C} 2$ & $\mathrm{C} 1$ & None $\ddagger$ & None $\neq$ & - & - & - & - & - & - \\
\hline Japan & B1 & .. & .. & $\mathrm{B} 2, \mathrm{C} 1$ & B2 & $\mathrm{C} 3$ & $\mathrm{~B} 3, \mathrm{~B} 4, \mathrm{C} 2$ & $\mathrm{C} 2$ & $\mathrm{C} 2$ & B4 & $\mathrm{C} 2$ & $\mathrm{~B} 4, \mathrm{C} 2$ & $\mathrm{C} 4, \mathrm{~B} 5$ & $\mathrm{C} 4$ & - & $\mathrm{C} 4$ & $\mathrm{C} 4$ & - \\
\hline Taiwan & .. & B1 & B1 & .. & .. & .. & .. & $\mathrm{C} 2^{*}, \mathrm{~B} 4 \dagger$ & B4 & $B 4^{*}$ & B4 & $\mathrm{B} 4, \mathrm{C} 4 \dagger$ & $\mathrm{B} 4, \mathrm{~B} 5{ }^{+}$ & $\mathrm{C} 4^{*}$ & $\mathrm{C} 4^{*}, \mathrm{C}^{\dagger}$ & $\mathrm{C} 5$ & C5, B5 & $B 5^{*}$ \\
\hline Korea & .. & .. & .. & .. & .. & .. & .. & .. & .. & $\mathrm{C}^{*}$ & None $\ddagger$ & None $\ddagger$ & $\mathrm{C} 4$ & - & - & - & - & - \\
\hline Brunei & .. & .. & .. & .. & .. & .. & .. & .. & .. & - & - & - & - & - & - & B5 & - & - \\
\hline Vietnam & .. & .. & .. & .. & .. & .. & .. & .. & .. & - & - & - & - & - & $\mathrm{C} 1, \mathrm{C}_{4}, \mathrm{C}_{5}$ & - & - & - \\
\hline Thailand & .. & .. & .. & .. & .. & .. & .. & .. & .. & - & - & $\mathrm{C} 1$ & $\mathrm{C} 1$ & $\mathrm{C} 1$ & - & $\begin{array}{l}\mathrm{B} 5, \mathrm{C} 1, \\
\mathrm{C} 2, \mathrm{C} 4\end{array}$ & $\begin{array}{l}\mathrm{B} 5, \mathrm{C} 1, \mathrm{C} 2 \\
\mathrm{C} 4, \mathrm{C} 5\end{array}$ & $\begin{array}{l}\mathrm{B} 5 \mathrm{t}, \mathrm{C} 1, \\
\mathrm{C} 2+, \mathrm{C} 4\end{array}$ \\
\hline China & .. & .. & .. & .. & .. & .. & $\mathrm{C} 3$ & $\mathrm{C} 4$ & .. & $\mathrm{C} 4$ & $\mathrm{C} 4$ & $\mathrm{C} 4$ & $\mathrm{C} 4$ & $\mathrm{C} 4$ & - & - & $\mathrm{C} 4$ & $\mathrm{C} 4$ \\
\hline
\end{tabular}

\section{Asia-Pacific region}

After the Australian and Japanese EV71 epidemics of the 1970 s, further small epidemics and sporadic clusters occurred in Hong Kong in 1985, ${ }^{43}$ and in Australia in 1986. ${ }^{44}$ In 1997, a large outbreak of EV71 in Sarawak, Malaysia, heralded the start of a new series of outbreaks across the Asia-Pacific region (table 2). ${ }^{9-14,45-53}$

In Sarawak, 2618 HFMD cases and 34 deaths were recorded between May and July, 1997; around the same time EV71 caused four deaths in peninsular Malaysia and several cases of severe neurological disease in Japan., ${ }^{411,54}$ In 1998, the largest EV71 epidemic so far occurred in Taiwan: ${ }^{7}$ an estimated 1.5 million people were infected and 405 children were admitted to hospital for serious neurological complications, of whom 78 died. The latest large Asian-Pacific epidemic was in China in 2008, when around 490000 infections and 126 deaths in children were reported; at the epicentre in Anhui Province, more than 6000 HFMD cases and 22 deaths in children were reported. ${ }^{12}$ In addition to these very large outbreaks, many areas, including Japan, Sarawak, Singapore, Taiwan, and Vietnam, have experienced cyclical epidemics that occur every 2-3 years (figure 2)..$^{55-57}$

Brainstem encephalitis, especially affecting the medulla, associated with cardiopulmonary dysfunction has become a notable feature in EV71 epidemics in Asia, and is the primary cause of death. ${ }^{4,9,12,17,58}$ This presentation is in contrast to that in the $1980 \mathrm{~s}$, when aseptic meningitis was the most frequent neurological involvement. ${ }^{36,37}$ Children typically present with a brief febrile illness and mild neurological signs, after which they develop signs of tachycardia, poor perfusion, and tachypnoea that rapidly develop into acute, intractable cardiac dysfunction and fulminant-in many cases fatal-pulmonary oedema or haemorrhage. ${ }^{19}$ Neurogenic pulmonary oedema is thought to be the main pathogenic process. ${ }^{17,18,54,59}$

\section{Other regions}

Outside the Asia-Pacific region, EV71 has continued to circulate at a low level in Africa, Europe, and the USA and causes sporadic cases or small outbreaks. During a 1-year prospective study in Canada in 1998, 20 children with EV71 were admitted to a tertiary hospital, mostly in the summer or autumn months; half had aseptic meningitis, and a third had respiratory symptoms, but no symptoms were severe and all improved rapidly. ${ }^{60}$ Two small community outbreaks of neurological EV71 disease, without HFMD, occurred in 2003 and 2005 in Denver, CO, USA, affecting 16 children aged 4 weeks to 9 years; one child died. ${ }^{61} \mathrm{~A}$ retrospective analysis of stool samples collected from children admitted to hospital with aseptic meningitis in Austria between 2001 and 2004 showed that EV71 was detected in 16 (9\%) of $181 . .^{62}$ A similar study identified 32 sporadic cases of EV71 infection in the UK between 1998 and 2006, presenting primarily as neurological disease, HFMD, or both..$^{63}$ In the Netherlands, 58 people were admitted to hospital with EV71-associated fever, gastrointestinal symptoms, and CNS infections in 2007, after 21 years of low endemicity. ${ }^{3}$ Widespread asymptomatic circulation of EV71 was also noted between October 2002 and October 2003 in Norway, where the virus was isolated from 19 (17\%) of 113 well children. ${ }^{64}$ EV71 was among a range of enteroviruses detected by the screening of blood donations in Scotland over 22 months; the detection rate for any enterovirus was one per 4000 donations, ${ }^{65}$ although the importance of this finding remains uncertain. In Nairobi, Kenya, two small institutional outbreaks of EV71 infection were reported in an HIV orphanage in 1999 and $2000 .^{66}$

\section{Molecular epidemiology}

Gene groups, evolution, and geographical distribution

Phylogenetic analysis suggests that EV71 emerged from the coxsackievirus type A 16 , as recently as $1940 . .^{32}$ The 
first complete phylogenetic analysis of EV71 based on the structural VP1 gene identified three independent lineages of EV71, designated A, B, and $\mathrm{C} ;{ }^{53}$ each group has at least $15 \%$ divergence from the others. Group A consists of one member, the prototype $\mathrm{BrCr}$ strain, which was first identified in California, USA, in 1970, and was not reported outside the USA until 2008, when isolates were reported from five of 22 children presenting with HFMD in Anhui province of central China. ${ }^{67}$ Sequencing of the complete VP1 gene showed very little divergence between isolates. The virus might, therefore, have been circulating undetected in central China, with very little evolutionary change for 40 years, although the source of the virus templates that were sequenced could

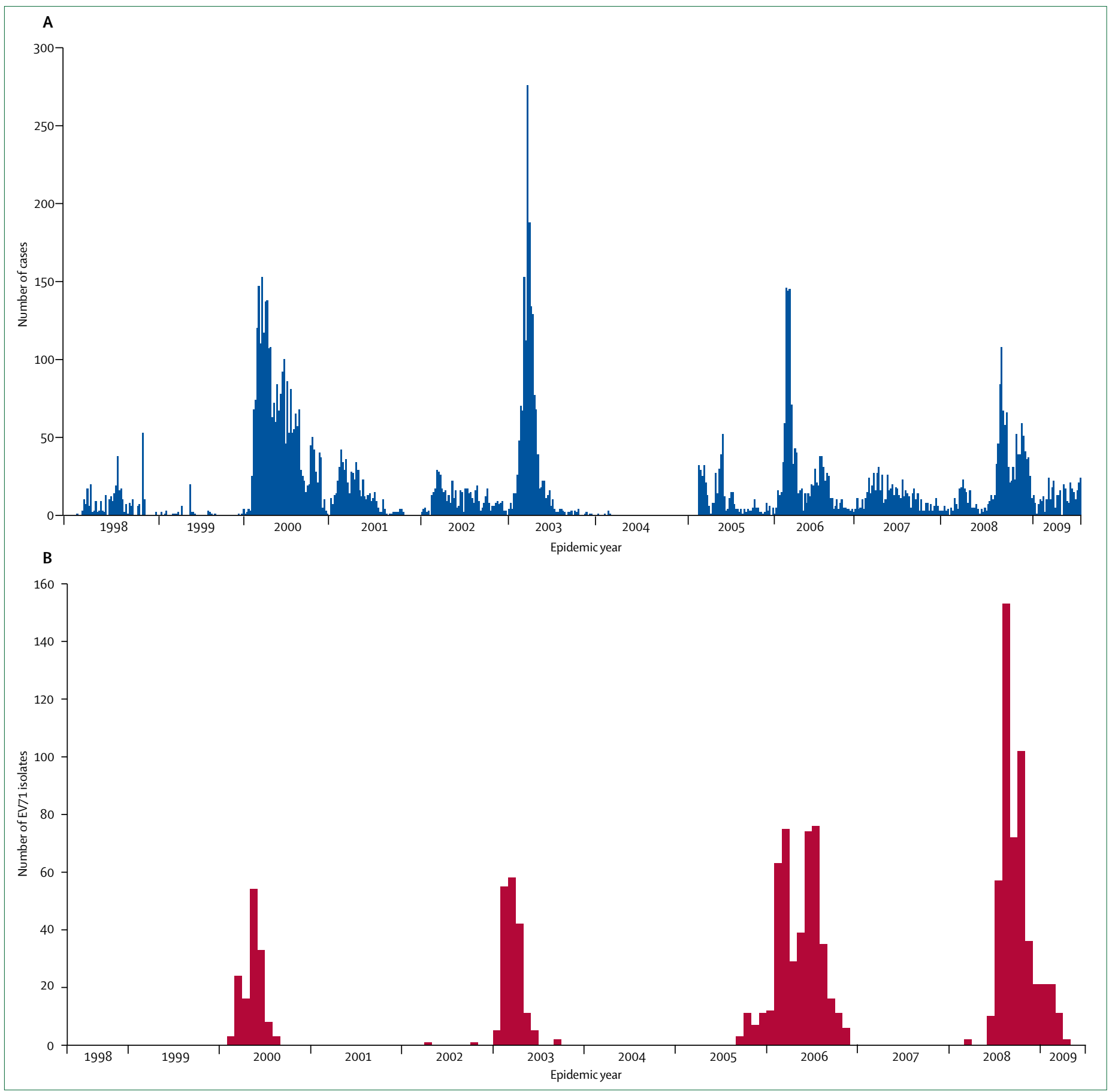

Figure 2: Distribution of (A) hand, foot, and mouth disease and (B) enteroviruse 71 isolates identified in sentinel clinics in Sarawak, Malaysia, from March, 1998 , to mid-2009 
have affected the results. Surveillance data from the same outbreak by the Chinese Center for Disease Control and Prevention do not seem to indicate any group A viruses. ${ }^{12}$ Good surveillance programmes are needed in many different geographical regions to provide accurate and relevant information about EV71 transmission and evolution, and to confirm whether group A viruses have re-emerged.

The B group has been predominant in Malaysia and Singapore, whereas the $\mathrm{C}$ group has been so in east Asia,

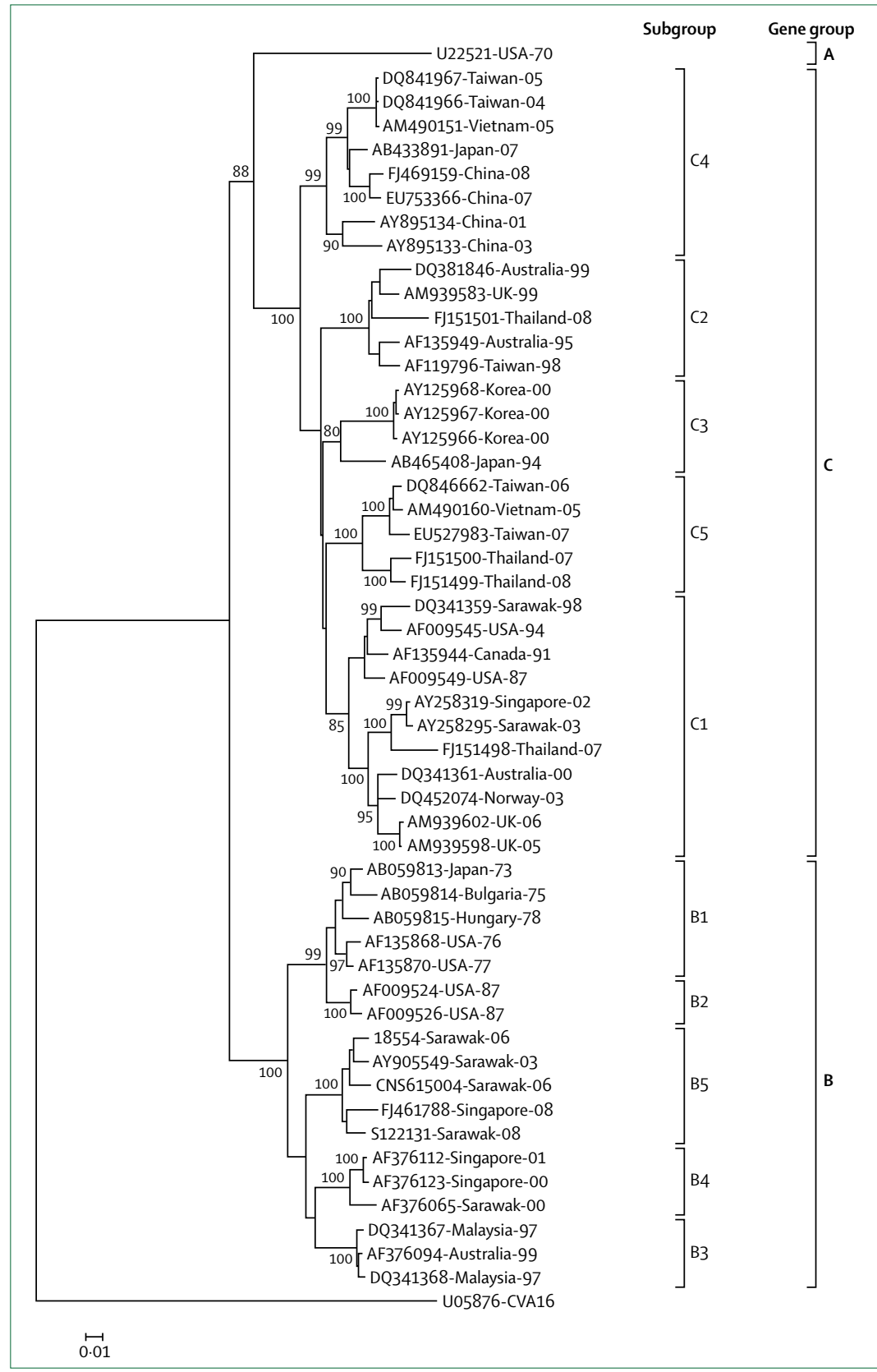

Figure 3: Phylogenetic analysis of enterovirus 71 VP1 gene sequences

A neighbour-joining tree constructed with the Kimura-2 parameter as a model for nucleotide substitution. The robustness of the tree was determined by bootstrapping, with use of 1000 pseudoreplicates. especially in mainland China and Vietnam (figure 3). Group B viruses, which were initially separated into subgroups, B1 and B2, owing to $12 \%$ divergence at the nucleotide level, were the predominant circulating strains in the 1970s and 1980s. ${ }^{53}$ Group C viruses, which were initially separated into the $\mathrm{C} 1$ and $\mathrm{C} 2$ subgroups, were identified in the mid-1980s (figure 3). Several subgroups have been added to groups $\mathrm{B}$ and $\mathrm{C}$ in the past 12 years, according to findings in the Asia-Pacific region (figure 3 , table 2). Viruses in subgroups B3 and B4 are thought to have both circulated in the region since $1997^{13,14,45}$ Subgroup B5, was first isolated in Japan and Sarawak in 2003, caused epidemics in Brunei, Sarawak, and Taiwan in 2006. ${ }^{46,55,56,68}$ Except for the major community outbreak in Sydney in 1986, subgroup C1 viruses have been isolated mainly from sporadic cases since the mid-1980s, which suggests low-level circulation worldwide. ${ }^{53,69}$ Subgroup C2 viruses caused the outbreak in 1998, and an outbreak in Perth, Australia, in 1999..$^{8,13,47,70}$ Subgroup C3 was isolated in Japan in 1994, and in Korea in 2000..$^{13,16,71}$ Subgroup C4 has been the predominant circulating subtype in mainland China since 2000, and has been reported in Japan, Vietnam, and Taiwan. ${ }^{9,12,14,47}$ Subgroup C5 has been reported in southern Vietnam and Taiwan. ${ }^{9,46} \mathrm{~A}$ genetically distinct EV71 strain (R13223, Genbank accession number AY179600 to AY179602), with no genetic relationship to other EV71 strains, was isolated in India in 2001 from one child with acute flaccid paralysis. ${ }^{72}$

\section{Transmission and epidemic potential}

Surveillance systems for EV71 established in several countries in the Asia-Pacific region, mainly to monitor transmission and spread, have provided information on virus evolution during outbreaks. In Sarawak, viral activity has increased every 3 years since 1997. This pattern is closely associated with increases in community incidence of HFMD. ${ }^{55}$ Regular cyclical epidemics have also been seen in Fukushima Prefecture, Japan. ${ }^{57}$ Such cyclical activity is assumed to relate to the availability of new birth cohorts of children who have not been exposed to the virus. ${ }^{73,74}$ Prediction of the epidemic potential of particular genotypic subgroups has proved difficult, although some differences in virulence, judged by size of associated epidemics, exist.

Shifts in subgroup dominance have been reported in Sarawak and Vietnam..$^{9,135}$ In Japan and Taiwan subgroups of the $\mathrm{B}$ and $\mathrm{C}$ viruses have caused epidemics at different times (table 2) $\cdot^{46,4775}$ By contrast, in the Netherlands group B viruses were predominant before 1986, but since 1987 dominance has shifted to group $\mathrm{C}$ viruses; crossneutralisation among the group $\mathrm{B}$ but not group $\mathrm{C}$ viruses is a possible explanation, although experimental data seem not to support this theory. ${ }^{3,6-78}$ Older subgroups of EV71 have been circulating and causing low levels of disease for many years, whereas some of those in newly described subgroups, such as B5, possess antigenicity distinct from other viruses and might, therefore, have the potential to 
cause very large outbreaks. ${ }^{48,76}$ Although outbreaks have so far been confined to the Asia-Pacific region, increasing rates of travel mean that every region could be at risk.

\section{Recombination}

Recombination events occur frequently within enterovirus species ${ }^{79}$ and recombination between EV71 viruses, and occasionally between EV71 and other enteroviruses, such as coxsackievirus types A 16 and A 8, has also been reported. ${ }^{48,80}$ Since recombination most often involves non-structural gene regions or untranslated regions, the use of PCR that amplifies the VP1 gene region is thought to be robust for diagnosis.

\section{Pathogenesis \\ Viral determinants of virulence}

The factors that determine whether EV71 infection will be asymptomatic or lead to HFMD or severe neurological disease are unknown. For polioviruses, the $5^{\prime}$ untranslated region and VP1 genes contain virulence determinants. ${ }^{26}$ Several studies have, therefore, examined the relevant nucleotide sequences or the whole genome to compare isolates from fatal and non-fatal cases, but most isolates have been identical or nearly identical. ${ }^{81,82}$ The frequency of CNS disease and other severe complications of EV71 infection has varied between Asian outbreaks, which suggests differences in virulence of subtypes. However, comparisons of outbreak data have been hampered by differences in study designs and viral diagnostic capabilities.

Perhaps the strongest data that determinants of strain virulence have key roles in the pathogenesis of severe neurological disease come from outbreaks in Perth, Australia, and Sarawak. In Perth, in 1999, subgroups B3 and C2 were both circulating. ${ }^{45,70} \mathrm{C} 2$ viruses linked to the Taiwan epidemic of 1998 were almost exclusively isolated from children with severe neurological disease, and only one isolate came from a case of uncomplicated HFMD. ${ }^{45,70}$ By contrast, B3 viruses, which were similar to those from the Sarawak 1997 epidemic, were isolated mainly from children with uncomplicated HFMD, aseptic meningitis, or those with neurological complications, none of whom died. ${ }^{8}$ In two discrete epidemics in Sarawak in which either B4 or B5 viruses were predominant, a study of 277 children with EV71associated HFMD showed that B4 viruses were less likely than B5 viruses to cause CNS infection or be part of a family cluster. ${ }^{83}$

\section{Dual infection}

During the 1997 EV71 B3 virus outbreak in Sarawak, an adenovirus type 21 was isolated in the patients who died and in some with acute flaccid paralysis. ${ }^{4,84}$ The virus was detected at autopsy in sterile sites, such as cerebrospinal fluid and brain and heart tissue, in more patients than EV71. This finding led to the suggestion that death was related to dual infection, ${ }^{4}$ but subsequent detailed studies, including longitudinal studies from Sarawak, have found no evidence of adenovirus 21 infection in other HFMD or neurological cases. Dual infection with EV71 and other viruses, including dengue and Japanese encephalitis, has been reported. ${ }^{83}$ Furthermore, adenovirus 21 has not been isolated in Sarawak since 1997.

\section{Host susceptibility}

Various factors could affect pathogenesis, especially partial cross-protective immunity from previous outbreaks, which might partly explain why young age is a risk factor for severe disease. ${ }^{73,74,85}$ One genetic study in Taiwan reported that HLA-A33 is associated with increased susceptibility to EV71 infection, although the role of MHC remains unknown. ${ }^{86}$ The researchers noted that HLA-A33 is more frequent in Asian populations than in white populations, which might explain the high number of EV71 epidemics in Asia. They suggested also that HLA-A2, in a mechanism yet to be defined, could be linked to the risk of cardiopulmonary failure in patients with EV71. ${ }^{86}$ The CTLA4 gene is an important regulator of T-cell cytotoxicity, and it has a role in the regulation of an immune response. In a study of 78 children with EV71 infection in Taiwan, those with meningoencephalitis had a higher frequency of G/G genotype at position 49 of exon 1 in this gene, than those without meningoencephalitis and controls. ${ }^{87}$ However, a subsequent study found no such association. ${ }^{86}$

\section{Pathophysiology of severe disease \\ Virus entry and spread}

EV71 is transmitted predominantly via the faeco-oral route, but can also spread through contact with viruscontaminated oral secretions, vesicular fluid, surfaces or fomites, and in respiratory droplets. ${ }^{1}$ As with other enteroviruses, initial viral replication is presumed to occur in the lymphoid tissues of the oropharyngeal cavity (tonsils) and small bowel (Peyer's patches), with further multiplication in the regional lymph nodes (deep cervical and mesenteric nodes), giving rise to a mild viraemia. Most infections are controlled at this point and remain asymptomatic. Further dissemination of enteroviruses to the reticuloendothelial system (liver, spleen, bone marrow, and lymph nodes), heart, lung, pancreas, skin, mucous membranes, and CNS coincides with the onset of clinical features. For EV71, viral shedding from the throat can occur up to 2 weeks after an acute EV71 infection, and virus can be isolated from stool for up to 11 weeks. ${ }^{88}$

Epidemiological and experimental studies suggest that polioviruses can invade the CNS system through a disrupted blood-brain barrier or retrograde axonal spread along cranial or peripheral nerves. For EV71, studies in mice and assessment of the distribution of virus and inflammation in fatal human cases implicate the latter route..$^{88-91}$ 


\section{Pathological findings}

CNS inflammation predominantly affects grey matter of the spinal cord and the whole medulla oblongata, including the dorsal nucleus of the vagus,
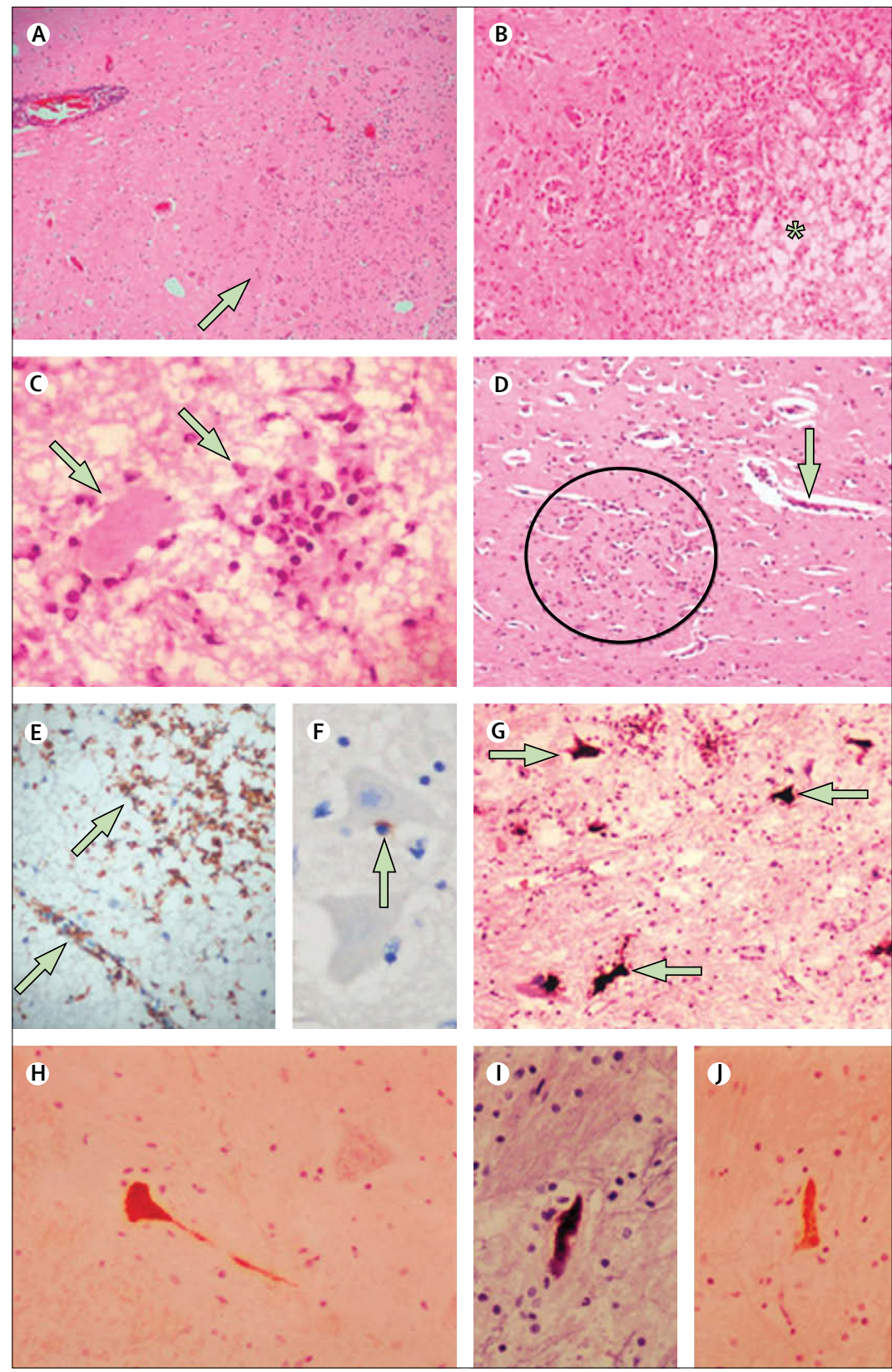

Figure 4: Pathological findings in enterovirus 71 encephalitis

(A) Parenchymal inflammation (arrow) and perivascular cuffing in the the medulla. Severely inflamed areas show (B) oedema (asterisk) and (C) neuronophagia (arrows). (D) More-subtle inflammation can be seen in the motor cortex, with mild perivascular cuffing (arrow) and parenchymal inflammatory cells (circle). (E) Numerous CD68-positive macrophages/microglia (arrows). (F) A CD8-positive lymphocyte adjacent to a neuron (arrow) (G) Viral RNA in the anterior horn cells of the spinal cord (arrows). (H) Viral antigens in the neuronal body and process in the hypothalamus. (I) Adjacent section of the same neuron that was positive for viral RNA, and (J) adjacent section that was positive for antigen. Stains: haematoxylin and eosin (A-D), immunohistochemistry/ peroxidase/DAB (E, F), and ISH/nitroblue tetrazolium/5-bromo-4-chloro-3-indolyl phosphate (G). Original magnifications: $\times 4(A), \times 10(B$ and $D), \times 40(C$ and F), and $\times 20(G)$. Modified from the Journal of Neuropathololgy and Experimental Neurology, ${ }^{90}$ with permission of Wolters Kluwer. tractus solitarius, the nucleus, and reticular formation The hypothalamus and subthalamic and dentate nuclei, and to a lesser degree motor cortex of the cerebrum, are

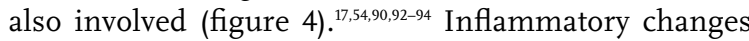
were absent in cerebellar cortex, thalamus, basal ganglia, peripheral nerve, and autonomic ganglia. Histopathological changes, characterised by perivascular cuffs, variable oedema, neuronophagia, and microglia nodules, are similar to those in encephalitis caused by other viruses. ${ }^{95}$ However, virus inclusion has not been observed, and viral antigens and RNA can be seen in only a few neuronal processes and phagocytic cells. ${ }^{90}$

\section{Severe pulmonary oedema and heart failure}

Although fulminant pulmonary oedema is preceded by and closely associated with CNS involvement, its cause is unclear, especially whether neurogenic pulmonary oedema, cardiac dysfunction, increased vascular permeability, and cytokine storm contribute (figure 5).

Neurogenic pulmonary oedema classically follows head injury. In these cases, raised intracranial pressure is thought to be important, but the pathogenesis is not completely understood. Experimental studies suggest that the hypothalamus, vasomotor centres of the medulla, and nuclei in the cervical spinal cord are important; lesions to various nuclei in these regions can increase activity along the sympathetic trunk, resulting in severe systemic and pulmonary hypertension and pulmonary oedema. ${ }^{96}$ Damage to brainstem nuclei in poliomyelitis is thought to lead to pulmonary oedema of neurogenic origin. ${ }^{97}$ Thus, when severe pulmonary oedema was first seen in EV71 encephalitis along with brainstem inflammatory changes, oedema was thought to be neurogenic. Postmortem examination and MRI studies of children with EV71 brainstem encephalitis showed extensive inflammation of grey matter of the spinal cord and the whole medulla oblongata. 17,54,90,93,94 The observations of hyperglycaemia and leucocytosis were also postulated to be due to increased sympathetic discharges..$^{98}$

Severe systemic and pulmonary hypertension is not always seen in children with EV71-associated pulmonary oedema. ${ }^{99-101}$ This disparity might arise because the changes in vascular pressures in neurogenic pulmonary oedema are only transient. ${ }^{96}$ Some commentators have argued that cardiac dysfunction is a major contributor to the pulmonary oedema. Although no histological or virological evidence of viral myocarditis is seen in patients with EV71 infection, raised concentrations of cardiac-specific troponin I suggest a degree of cardiac damage..$^{18,54,101,102}$ An echocardiographic study in 11 children with EV71 brainstem encephalitis showed that cardiac function was impaired, indicated by substantially lowered left-ventricular ejection fractions. ${ }^{10}$ Two children whose cardiac output was supported with a left-ventricular assist device survived, whereas all the others died..$^{103}$ In a separate report the same researchers described very high concentrations of norepinephrine 
and epinephrine in three of the 17 children with leftventricular dysfunction. ${ }^{101}$

Although patients with EV71 infection do not have myocardial inflammation, histological examination of cardiac ventricular tissue biopsy samples from six fatal cases and one survivor revealed notable coagulative myocytolysis, myofibrillar degeneration, and cardiomyocyte apoptosis, which are the characteristic features of catecholamine-associated cardiotoxic effects. ${ }^{101,104}$ Thus, high catecholamine concentrations caused by brainstem encephalitis are purported to have a direct effect on cardiac function, as well as to cause pulmonary oedema via raised pulmonary pressures.

The other potential contributor to pulmonary oedema, increased vascular permeability, might arise secondary to the systemic inflammatory response. Several studies have examined cytokine and chemokine profiles in EV71 patients with brainstem encephalitis: concentrations of interleukins $1 \mathrm{~B}, 6,10$, and 13 , tumour necrosis factor $\alpha$, and interferon $\gamma$ are all significantly higher in patients with EV71 with pulmonary oedema than in those without. Several of these cytokines are mediators of increased

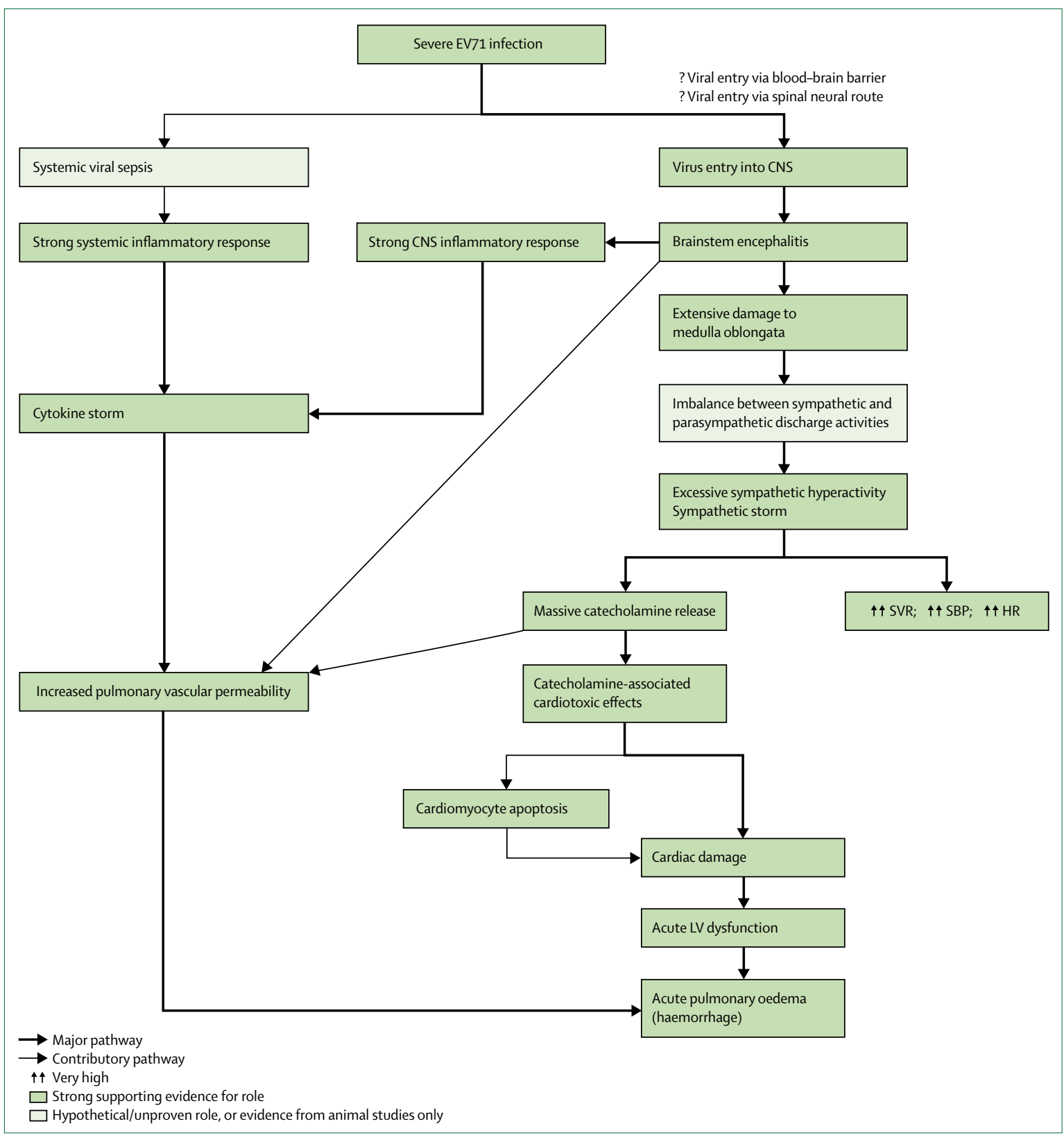

Figure 5: The postulated pathogenesis of enterovirus-71-associated acute pulmonary oedema

EV71=enterovirus 71. CNS=central nervous system. SVR=systemic vascular resistance. $S B P=$ systemic blood pressure. $H R=$ heart rate. $L V=l e f t$ ventricular. 
vascular permeability ${ }^{105-107}$ High concentrations of several chemokines in plasma, including $10 \mathrm{kDa}$-interferon- $\gamma$ induced protein, monocyte chemoattractant protein, monokine induced by interferon $\gamma$, and interleukin 8 , have been reported in children with brainstem encephalitis and pulmonary oedema. ${ }^{108}$ Children with oedema also had depleted lymphocyte populations, especially CD4, CD8, and natural killer cells. ${ }^{87,107}$ Thrombocytosis, neutrophilia, and hyperglycaemia are all thought to reflect a systemic inflammatory response..$^{105,107}$ Cytokines in the cerebrospinal fluid are less studied than those in blood, but in one study patients with encephalitis complicated by oedema had high concentrations of interleukin $1 b$, compared with those who had encephalitis alone..$^{105}$

The development of pulmonary oedema in patients with EV71 encephalitis seems to be strongly associated with dysregulation of systemic and CNS inflammatory responses. This relation has formed at least part of the basis for anti-inflammatory therapy with intravenous immunoglobulin, and the approach does seem to be effective. . $^{83,99,109-111}$

The exact mechanism for pulmonary oedema in EV71 encephalitis is unclear. Neurogenic mechanisms secondary to brainstem inflammation seem to be important, but pathologically similar changes are seen in other encephalitides, such as Japanese encephalitis, without pulmonary oedema being such a prominent feature. Cardiac dysfunction and the effects of the systemic inflammatory response on the vascular endothelium may also make important contributions. In-vivo models, including those in mice and nonhuman primates, have replicated some of the features of severe EV71 disease, such as neuroinvasion with inflammatory changes, but none has yet been able to reproduce the severe systemic features, such as pulmonary oedema. ${ }^{89-91,112-114}$

\section{Prospects for control}

\section{Surveillance and social distancing}

The only measures available for disease control are public health approaches. Since early intervention can lessen the spread of the virus, many countries in the Asia-Pacific region, including Japan, Malaysia, Singapore, Taiwan, and Vietnam, have implemented heightened surveillance for EV71. ${ }^{15,55,56,115,116}$ HFMD has now become a notifiable disease in many countries in the region. ${ }^{116}$ However, since other enteroviruses, such as coxsackievirus types A 8 , A 10 , and A 16, can cause HFMD, concurrent virological surveillance is necessary. This approach can also provide invaluable molecular epidemiological data that might help to track the spread of the virus across the region.

Outbreak control measures are primarily targeted at interrupting virus transmission person to person and through contact with contaminated surfaces, toys, or fomites. Health education, therefore, focuses on personal hygiene and good sanitation, including frequent hand washing, proper disposal of soiled nappies, and disinfection of soiled surfaces with chlorinated (bleach) disinfectants.

The transmission of enteroviruses, including EV71, is most efficient in crowded settings and, therefore, most countries in the region, including Malaysia, Singapore, Taiwan, Hong Kong, and China, have adopted social distancing measures, such as closures of childcare facilities and schools, and cancellation of public functions involving children. ${ }^{115,16}$ Little systematic research has been done to assess the effectiveness of such measures, but one study from Singapore seemed to show some benefit. ${ }^{115}$ However, the optimum timing for implementation-as soon as an HFMD outbreak is reported or after it is confirmed to be caused by EV71-is unclear. In addition, the effectiveness of distancing measures, which have substantial socioeconomic implications, is uncertain. If EV71 is like other directly transmissible viruses, such controls will decrease the peak incidence of disease, but the outbreak could be prolonged and, therefore, the overall number of cases might not be lowered (Cardosa MJ, unpublished; figure 6). Transmission of the virus within families rather than the peer-group at school could lead to increased incidence of severe cases, as the inoculum concentration is thought to be higher. ${ }^{85}$ Data from clinical and epidemiological studies are needed to guide public health decisions.

\section{Vaccine development}

No vaccines against EV71 exist, but by analogy with poliomyelitis, vaccination probably offers the best option for disease control. One limitation in EV71 vaccine development is the lack of a good mouse model of human disease. Adult mice are resistant to infection. Although suckling mice are susceptible, by the time immunity develops after inoculation, the animals have matured and become resistant to infection. One way around this issue is to vaccinate female adult mice, allow them to become pregnant, and then measure titres of protective maternal antibodies transferred to offspring, as judged by protection against lethal infection. ${ }^{17}$

In human beings the target population should be young children, especially those younger than 3 years, because they are the most susceptible to severe disease. One important issue is whether vaccines derived against one EV71 genetic subgroup will provide cross-protection against all others; available data are contradictory. ${ }^{76-78}$ Several comprehensive reviews on the development of EV71 vaccine candidates have been published. ${ }^{118,119}$ Various types of vaccines are being investigated, including inactivated whole-virus, live attenuated, subviral particle, and DNA vaccines. All types are in early stages of development, with the most advanced undergoing preclinical trials in mice and non-human primates.

Candidate inactivated vaccines include those derived in Taiwan from the B4 viruses EV71-075 and EV71-0117, which are highly immunogenic, and from EV71-1207, which is a C2 virus and is less immunogenic. In one 


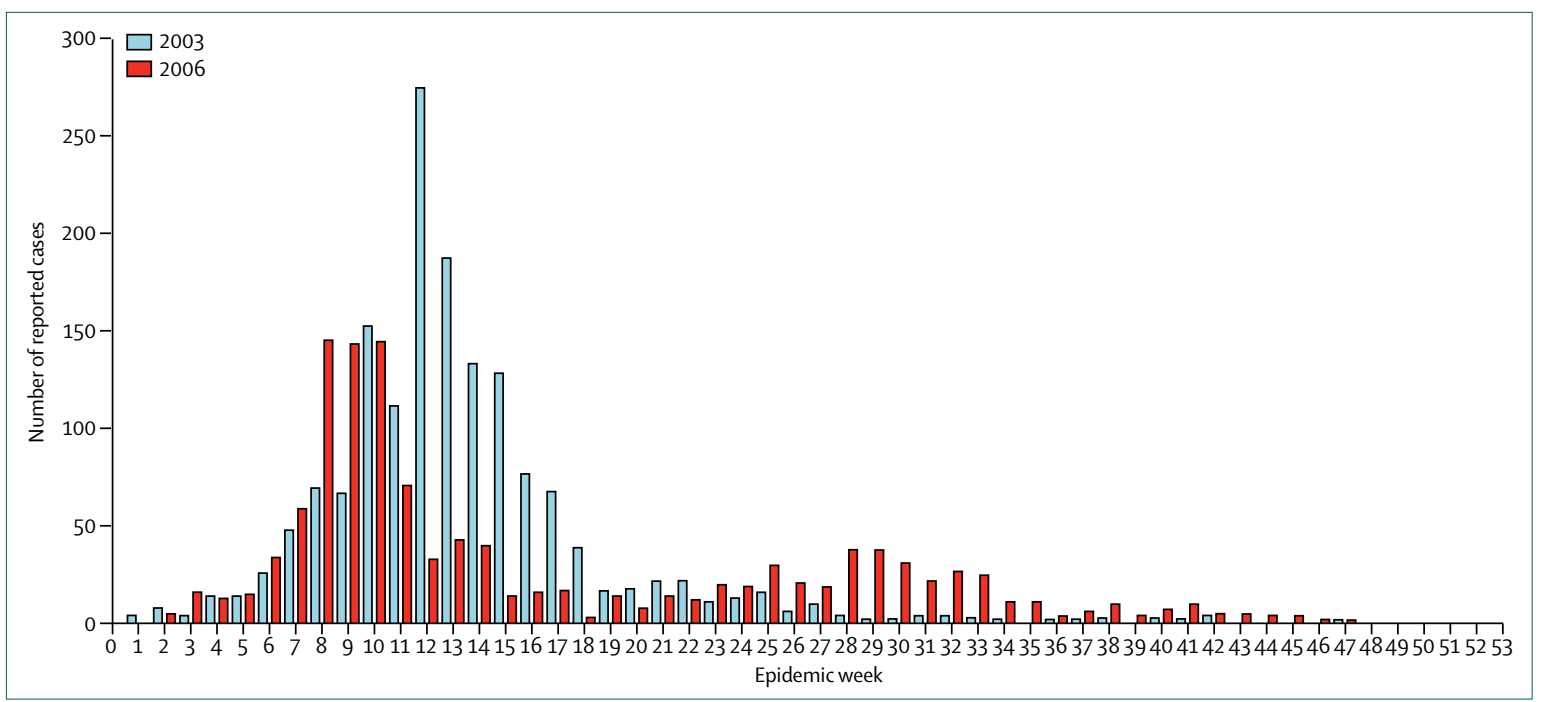

Figure 6: Comparison of data from sentinel surveillance centres on effects of public health interventions on hand, foot, and mouth disease in Sarawak, Malaysia, in 2003 and 2006

The public health response was limited in 2003, but more-rigorous social distancing measures were encouraged in 2006.

study all these vaccines were more immunogenic in mice than recombinant VP1 protein or DNA vectored vaccines. ${ }^{120}$ Virus-like particles for EV71, which resemble the virus in appearance and capsid and protein structure, have been produced and purified as potential vaccines. ${ }^{121}$ After immunisation of BALB/C mice, the particles induced potent and long-lasting humoral immune responses, reflected by high total IgG and neutralisation titres. Splenocytes collected from the immunised mice exhibited substantial cell proliferation and stimulated production of interferon $\gamma$ and interleukins 2 and 4, indicating the induction of T-helper-1 and T-helper-2 immune responses. Immunisation of female mice conferred protection (survival up to $89 \%$ ) to neonatal mice against virus challenge with a dose 1000 times that normally required to kill $50 \%$ of animals. ${ }^{121}$

A potential DNA vaccine has been developed by inserting the VP1 gene into the pVAX1 vector, and transforming the constructs into Escherichia coli cells, followed by expression in a mammalian cell line. ${ }^{122}$ Immunisation of mice with the DNA vaccine constructs resulted in the production of antibodies to VP1 IgG and neutralising antibody against EV71. Oral immunisation of female mice with an attenuated Salmonella enterica serovar Typhimurium expressing the VP1 gene, also proved protective in newborn offspring. ${ }^{123}$ Transgenic tomatoes expressing the VP1 protein have been developed. Incorporation of this protein in an oral vaccine led to the development of VP1-specific antibodies and evidence of cell-mediated immunity in BALB/c mice, and provided protection to offspring in neonatal challenge models. ${ }^{124}$

Linear neutralising epitopes from the VP1 capsid protein were identified in mice by raised concentrations of antisera against overlapping peptides from this protein, two of which elicited neutralising antibody responses. ${ }^{125}$ One of these peptides, SP70, was especially potent, and comparison with sequences from other strains showed it was conserved among the different genotypic subgroups of EV71, which suggests it is a promising vaccine candidate.

A live attenuated strain of EV71, EV71(S1-3), was derived from the genotype A prototype strain $\mathrm{BrCr}$ by genetic manipulation, ${ }^{126}$ on the basis of temperature-sensitive determinants of poliovirus type 1 vaccine strain, some of which are located in the $5^{\prime}$ and $3^{\prime}$ untranslated regions and the 3 Dpol gene. Intravenous inoculation of cynomolgus monkeys led to the production of antibodies with cross-reactivity against a broad spectrum of EV71 genotypes that survived challenge with intravenous virulent EV71 (BrCr-TR strain), which is lethal to nonimmunised monkeys. However, the vaccine strain itself caused mild neurological symptoms (tremor) and entered the spinal cord, which indicated that further work on attenuation is needed. ${ }^{126}$

Among the various vaccine candidates, inactivated whole virus vaccines are in some ways the most ready to develop further, because the principles of vaccines based on inactive whole virus are well established. However, experience with vaccination against Japanese encephalitis, another major neurological infection in Asia, has shown that issues over cost and availability can limit the widespread uptake of vaccines in poor Asian countries. If a vaccine is to be used across the whole of Asia, it needs to be cheap, easily produced, and readily available. ${ }^{127}$

\section{Conclusions}

The increased size and frequency of EV71 outbreaks in the Asia-Pacific region over the past 12 years has been an important public health issue. Molecular epidemiological studies suggest that some viral genotypic subgroups seem 
to have massive potential for explosive epidemics, whereas others have more-indolent, low-level circulation. However, the biological determinants of these differences are poorly understood. The reasons for epidemiological differences between EV71 in the Asia-Pacific region and that in Europe and the USA are also unclear, as are the virological and host determinants of the wide-ranging clinical phenotypes in infected individuals. Although some animal models of neurological disease caused by EV71 are reasonable, a good model of cardiorespiratory dysfunction is urgently required to help understand pathogenesis better.

The public health measures currently used during EV71 epidemics are empirical and generic, have high socioeconomic impact and are not clearly effective. Further research is needed on virus transmission. The identification of several EV71 receptors might help in drug discovery. Several vaccine candidates are under development, but the logistical issues of how to reach their target paediatric populations remain important.

\section{Contributors}

TS and MHO conceived and designed this Review. TS, PL, DP, MJC $\mathrm{PM}$, and MHO drafted the paper and critically revised it.

\section{Acknowledgments}

MHO is a Wellcome Trust Training Fellow. TS is an MRC Senior Clinica Fellow. We thank the Liverpool NIHR Biomedical Research Centre in Microbial Diseases for support.

\section{Conflicts of Interest}

MJC joined Sentinext Therapeutics, a Malaysian biotechnology start-up company involved in the development of a vaccine against enterovirus 71, as Chief Scientific Officer in September, 2010, but was not employed by the company during the design or preparation of this Review. TS, MJC, and MHO have acted as informal advisers to WHO on hand, foot, and mouth disease and enterovirus 71 infection.

PL, DP, and PM declare that they have no conflicts of interest.

\section{References}

1 Pallansch MA, Ross RP. Enteroviruses: polioviruses, coxsackieviruses, echoviruses, and newer enteroviruses. In: Knipe DM, Howley PM, Griffin DE, et al, eds. Fields Virology, vol 1. Hagerstown, MD, USA: Lippincott, Williams \& Wilkins, 2001; 1: 723-75.

2 Schmidt N, Lennette E, Ho H. An apparently new enterovirus isolated from patients with disease of the central nervous system. J Infect Dis 1974; 129: 304-09.

3 Van der Sanden S, Koopmans M, Uslu G, Van der Avoort H, on behalf of the Dutch Working Group for Clinical Virology. Epidemiology of enterovirus 71 in The Netherlands, 1963 to 2008. J Clin Microbiol 2009; 47: 2826-33.

4 Cardosa MJ, Krishnan S, Tio PH, Perera D, Wong SC. Isolation of subgenus B adenovirus during a fatal outbreak of enterovirus 71-associated hand, foot, and mouth disease in Sibu, Sarawak. Lancet 1999; 354: 987-91.

5 Chan K, Goh K, Chong C, Teo E, Lau G, Ling A. Epidemic hand, foot and mouth disease caused by human enterovirus 71, Singapore. Emerg Infect Dis 2003; 9: 78-85.

6 Chan L, Parashar U, Lye M, et al. Deaths of children during an outbreak of hand, foot, and mouth disease in Sarawak, Malaysia: clinical and pathological characteristics of the disease. Clin Infect Dis 2000; 31: 678-83.

7 Ho M, Chen ER, Hsu KH, et al. An epidemic of enterovirus 71 infection in Taiwan. N Engl J Med 1999; 341: 929-35.

8 McMinn P, Stratov I, Nagarajan L, Davis S. Neurological manifestations of enterovirus 71 infection in children during an outbreak of hand, foot, and mouth disease in Western Australia. Clin Infect Dis 2001; 32: 236-42.

9 Tu PV, Thao NT, Perera D, et al. Epidemiologic and virologic investigation of hand, foot, and mouth disease, southern Vietnam, 2005. Emerg Infect Dis 2007; 13: 1733-41.
10 Zhang Y, Tan X, Wang H, et al. An outbreak of hand, foot, and mouth disease associated with subgenotype $\mathrm{C} 4$ of human enterovirus 71 in Shandong. China J Clin Virol 2009; 44: 262-67.

11 Komatsu H, Shimizu Y, Takeuchi Y, Ishiko H, Takada H. Outbreak of severe neurologic involvement associated with Enterovirus 71 infection. Pediatr Neurol 1999; 20: 17-23.

12 Zhang Y, Zhu Z, Yang W, et al. An emerging recombinant human enterovirus 71 responsible for the 2008 outbreak of Hand Foot and Mouth Disease in Fuyang city of China. Virol J 2010; 7: 94.

13 Cardosa MJ, Perera D, Brown B, et al. Molecular epidemiology of human enterovirus 71 strains and recent outbreaks in the AsiaPacific region: comparative analysis of the VP1 and VP4 genes. Emerg Infect Dis 2003; 9: 461-68.

14 Shimizu H, Utama A, Onnimala N, et al. Molecular epidemiology of enterovirus 71 infection in the Western Pacific Region. Pediatr Int 2004; 46: 231-35.

15 Chen K, Chang H, Wang S, Cheng Y, Yang J. Epidemiologic features of hand-foot-mouth disease and herpangina caused by enterovirus 71 in Taiwan, 1998-2005. Pediatrics 2007; 120: 244-52.

16 Jee YM, Cheon DS, Kim K, et al. Genetic analysis of the VP1 region of human enterovirus 71 strains isolated in Korea during 2000. Arch Virol 2003; 148: 1735-46.

17 Huang CC, Liu CC, Chang YC, Chen CY, Wang ST, Yeh TF. Neurologic complications in children with enterovirus 71 infection. N Engl J Med 1999; 341: 936-42.

18 Chang LY, Huang YC, Lin TY. Fulminant neurogenic pulmonary oedema with hand, foot, and mouth disease. Lancet 1998; 352: 367-68.

19 Ooi MH, Wong SC, Lewthwaite P, Cardosa MJ, Solomon T. Clinical features, diagnosis and management of human enterovirus 71 infection. Lancet Neurol 2010; 9: 1097-1105.

20 Nasri D, Bouslama L, Pillet S, Bourlet T, Aouni M, Pozzetto B. Basic rationale, current methods and future directions for molecular typing of human enterovirus. Expert Rev Mol Diagn 2007; 7: 419-34.

21 Brown B, Oberste M, Maher K, Pallansch M. Complete genomic sequencing shows that polioviruses and members of human enterovirus species $\mathrm{C}$ are closely related in the noncapsid coding region. J Virol 2003; 77: 8973-84.

22 Brown BA, Pallansch MA. Complete nucleotide sequence of enterovirus 71 is distinct from poliovirus. Virus Res 1995; 39: 195-205.

23 Chen CH, Hsu BM, Wan MT. Molecular detection and prevalence of enterovirus within environmental water in Taiwan. J Appl Microbiol 2008; 104: 817-23.

24 Hsu BM, Chen CH, Wan MT. Prevalence of enteroviruses in hot spring recreation areas of Taiwan. FEMS Immunol Med Microbiol 2008; 52: 253-59.

25 Chan YF, Abu Bakar S. Virucidal activity of Virkon S on human enterovirus. Med J Malaysia 2005; 60: 246-48.

26 De Jesus NH. Epidemics to eradication: the modern history of poliomyelitis. Virol J 2007; 4: 70.

27 Yamayoshi S, Yamashita Y, Li J, et al. Scavenger receptor B2 is a cellular receptor for enterovirus 71. Nat Med 2009; 15: 798-801.

28 Nishimura Y, Shimojima M, Tano Y, Miyamura T, Wakita T, Shimizu H. Human P-selectin glycoprotein ligand-1 is a functional receptor for enterovirus 71. Nat Med 2009; 15: 794-97.

29 Yang B, Chuang H, Kuender DY. Sialylated glycans as receptor and inhibitor of enterovirus 71 infection to DLD-1 intestinal cells. Virol J 2009; 6: 141

30 Lin YW, Wang SW, Tung YY, Chen SH. Enterovirus 71 infection of human dendritic cells. Exp Biol Med (Maywood) 2009; 234: 1166-73.

31 Zhou T, Chen YC, Hao L, Zhang Y. DC-SIGN and immunoregulation. Cell Mol Immunol 2006; 3: 279-83.

32 Tee KK, Lam TT, Chan YF, et al. Evolutionary genetics of human enterovirus 71: origin, population dynamics, natural selection, and seasonal periodicity of the VP1 gene. J Virol 2010; 84: 3339-50.

33 Nobusawa E, Sato K. Comparison of the mutation rates of human influenza A and B viruses. J Virol 2006; 80: 3675-78.

34 Kew OM, Sutter RW, Nottay BK, et al. Prolonged replication of type 1 vaccine-derived poliovirus in an immunodeficient patient. J Clin Microbiol 1998; 36: 2893-99.

35 Deibel R, Flanagan TD. Central nervous system infections. Etiologic and epidemiologic observations in New York State, 1976-1977. N Y State J Med 1979; 79: 689-95. 
36 Kennett ML, Birch CJ, Lewis FA. Enterovirus type 71 infection in Melbourne. Bull World Health Organ 1975; 51: 609-15.

37 Blomberg J, Lycke E, Ahlfors K, Johnsson T, Wolontis S, von Zeipel G. New enterovirus type associated with epidemic of aseptic meningitis and-or hand, foot, and mouth disease. Lancet 1974; 2: 112.

38 Ishimaru Y, Nakano S, Yamaoka K, Takami S. Outbreaks of hand, foot and mouth disease by enterovirus 71 . High incidence of complication disorders of central nervous system. Arch Dis Child 1980; 55: 583-88.

39 Hagiwara A, Tagaya I, Yoneyama T. Epidemic of hand, foot and mouth disease associated with enterovirus 71 infection. Intervirology 1978; 9: 60-63.

40 Chumakov M, Voroshilova M, Shindarov L. Enterovirus 71 isolated from cases of epidemic poliomyelitis-like disease in Bulgaria. Arch Virol 1979; 60: 329-40.

41 Shindarov LM, Chumakov MP, Voroshilova MK. Epidemiological, clinical, and pathomorphological characteristics of epidemic poliomyelitis-like disease caused by enterovirus 71 . J Hyg Epidemiol Microbiol Immunol 1979; 23: 284-95.

42 Nagy G, Takatsy S, Kukan E, Mihaly I, Domok I. Virological diagnosis of enterovirus type 71 infections: experiences gained during an epidemic of acute CNS diseases in Hungary in 1978. Arch Virol 1982; 71: 217-27.

43 Samuda GM, Chang WK, Yeung CY, Tang PS. Monoplegia caused by enterovirus 71: an outbreak in Hong Kong. Pediatr Infect Dis J 1987; 6: 206-08.

44 Gilbert GL, Dickson KE, Waters MJ, Kennett ML, Land SA, Sneddon M. Outbreak of enterovirus 71 infection in Victoria, Australia, with a high incidence of neurologic involvement. Pediatr Infect Dis J 1988; 7: 484-87.

45 McMinn P, Lindsay K, Perera D, Chan H, Chan K, Cardosa MJ. Phylogenetic analysis of enterovirus 71 strains isolated during linked epidemics in Malaysia, Singapore, and Western Australia. J Virol 2001; 75: 7732-38.

46 Huang YP, Lin TL, Kuo CY, et al. The circulation of subgenogroups B5 and C5 of enterovirus 71 in Taiwan from 2006 to 2007. Virus Res 2008; 137: 206-12.

47 Lin KH, Hwang KP, Ke GM, et al. Evolution of EV71 genogroup in Taiwan from 1998 to 2005: an emerging of subgenogroup C4 of EV71. J Med Virol 2006; 78: 254-62.

48 Huang SW, Hsu YW, Smith DJ, et al. Reemergence of enterovirus 71 in 2008 in Taiwan: dynamics of genetic and antigenic evolution from 1998 to 2008. J Clin Microbiol 2009; 47: 3653-62.

49 Chua KB, Chua BH, Lee CS, et al. Genetic diversity of enterovirus 71 isolated from cases of hand, foot and mouth disease in the 1997, 2000 and 2005 outbreaks, Peninsular Malaysia. Malays J Pathol 2007; 29: 69-78.

50 Jeong EJ, Lee JH, Kim MS, et al. Molecular characterization of enteroviruses detected in Gyeong-Ju and Po-Hang provinces of Korea in 2003. Arch Virol 2010; published online July 18. DOI:10.1007/s00705-010-0755-4.

51 Chatproedprai S, Theanboonlers A, Korkong S, Thongmee C, Wananukul S, Poovorawan Y. Clinical and molecular characterization of hand-foot-and-mouth disease in Thailand, 2008-2009. Jpn J Infect Dis 2010; 63: 229-33.

52 Li L, He Y, Yang H, et al. Genetic characteristics of human enterovirus 71 and coxsackievirus A16 circulating from 1999 to 2004 in Shenzhen, People's Republic of China. J Clin Microbiol 2005; 43: 3835-89.

53 Brown BA, Oberste MS, Alexander JP Jr, Kennett ML, Pallansch MA Molecular epidemiology and evolution of enterovirus 71 strains isolated from 1970 to 1998. J Virol 1999; 73: 9969-75.

54 Lum LC, Wong KT, Lam SK, et al. Fatal enterovirus 71 encephalomyelitis. J Pediatr 1998; 133: 795-98.

55 Podin Y, Gias E, Ong F, et al. Sentinel surveillance for human enterovirus 71 in Sarawak, Malaysia: lessons from the first 7 years. BMC Public Health 2006; 6: 180.

56 Mizuta K, Abiko C, Murata T, et al. Frequent importation of enterovirus 71 from surrounding countries into the local community of Yamagata, Japan, between 1998 and 2003. J Clin Microbiol 2005; 43: 6171-5.

57 Hosoya M, Kawasaki Y, Sato M, et al. Genetic diversity of enterovirus 71 associated with hand, foot and mouth disease epidemics in Japan from 1983 to 2003. Pediatr Infect Dis J 2006; 25: 691-94.
58 Prager P, Nolan M, Andrews I, Williams G. Neurogenic pulmonary edema in enterovirus 71 encephalitis is not uniformly fatal but causes severe morbidity in survivors. Pediatr Crit Care Med 2003; 4: 377-81.

59 Lum LC, Wong KT, Lam SK, Chua KB, Goh AY. Neurogenic pulmonary oedema and enterovirus 71 encephalomyelitis. Lancet 1998; 352: 1391.

60 Merovitz L, Demers AM, Newby D, McDonald J. Enterovirus 71 infections at a Canadian center. Pediatr Infect Dis J 2000; 19: 755-57.

61 Perez-Velez CM, Anderson MS, Robinson CC, et al. Outbreak of neurologic enterovirus type 71 disease: a diagnostic challenge. Clin Infect Dis 2007; 45: 950-57.

62 Ortner B, Huang CW, Schmid D, et al. Epidemiology of enterovirus types causing neurological disease in Austria 1999-2007: detection of clusters of echovirus 30 and enterovirus 71 and analysis of prevalent genotypes. J Med Virol 2009; 81: 317-24.

63 Bible JM, Iturriza-Gomara M, Megson B, et al. Molecular epidemiology of human enterovirus 71 in the United Kingdom from 1998 to 2006. J Clin Microbiol 2008; 46: 3192-200.

64 Witso E, Palacios G, Ronningen KS, et al. Asymptomatic circulation of HEV71 in Norway. Virus Res 2007; 123: 19-29.

65 Welch J, Maclaran K, Jordan T, Simmonds P. Frequency, viral loads, and serotype identification of enterovirus infections in Scottish blood donors. Transfusion 2003; 43: 1060-66.

66 Chakraborty R, Iturriza-Gomara M, Musoke R, Palakudy T, D'Agostino A, Gray J. An epidemic of enterovirus 71 infection among HIV-1-infected orphans in Nairobi. AIDS 2004; 18: 1968-70.

$67 \mathrm{Yu} \mathrm{H}$, Chen W, Chang H, et al. Genetic analysis of the VP1 region of enterovirus 71 reveals the emergence of genotype A in central China in 2008. Virus Genes 2010; 41: 1-4.

68 AbuBakar S, Sam IC, Yusof J, et al. Enterovirus 71 outbreak, Brunei Emerg Infect Dis 2009; 15: 79-82.

69 Sanders SA, Herrero LJ, McPhie K, et al. Molecular epidemiology of enterovirus 71 over two decades in an Australian urban community. Arch Virol 2006; 151: 1003-13.

70 McMinn P. An overview of the evolution of enterovirus 71 and its clinical and public health significance. FEMS Microbiol 2002; 26: 91-107.

71 Iwai M, Masaki A, Hasegawa S, et al. Genetic changes of coxsackievirus A16 and enterovirus 71 isolated from hand, foot, and mouth disease patients in Toyama, Japan between 1981 and 2007. Jpn J Infect Dis 2009; 62: 254-59.

72 Deshpande JM, Nadkarni SS, Francis PP. Enterovirus 71 isolated from a case of acute flaccid paralysis in India represents a new genotype. Curr Sci 2003; 84: 1350-53.

$73 \mathrm{Lu}$ CY, Lee CY, Kao CL, et al. Incidence and case-fatality rates resulting from the 1998 enterovirus 71 outbreak in Taiwan. J Med Virol 2002; 67: 217-23.

74 Chang LY, King CC, Hsu KH, et al. Risk factors of enterovirus 71 infection and associated hand, foot, and mouth disease/herpangina in children during an epidemic in Taiwan. Pediatrics 2002; 109: e88.

75 Wang JR, Tuan YC, Tsai HP, Yan JJ, Liu CC, Su IJ. Change of major genotype of enterovirus 71 in outbreaks of hand-foot-and-mouth disease in Taiwan between 1998 and 2000 J Clin Microbiol 2002; 40: 10-15.

76 Van der Sanden S, Van der Avoort H, Lemey P, Uslu G, Koopmans M. Evolutionary trajectory of the VP1 gene of human enterovirus 71 genogroup B and C viruses. J Gen Virol 2010; 91: 1949-58.

77 Mizuta K, Aoki Y, Suto A, et al. Cross-antigenicity among EV71 strains from different genogroups isolated in Yamagata, Japan, between 1990 and 2007. Vaccine 2009; 27: 3153-58.

78 Kung SH, Wang SF, Huang CW, Hsu CC, Liu HF, Yang JY. Genetic and antigenic analyses of enterovirus 71 isolates in Taiwan during 1998-2005. Clin Microbiol Infect 2007; 13: 782-87.

79 Simmonds P, Welch J. Frequency and dynamics of recombination within different species of human enteroviruses. J Virol 2006; 80: 483-93.

80 Chan Y, Abu Baker S. Recombinant human enterovirus 71 in hand, foot and mouth disease patients. Emerg Infect Dis 2004; 10: 1468-70.

81 Shih S, Ho M, Lin K, et al. Genetic analysis of enterovirus 71 isolated from fatal and non-fatal cases of hand, foot and mouth disease during an epidemic in Taiwan, 1998. Virus Res 2000; 68: $127-36$. 
82 Singh S, Poh C, Chow V. Complete sequence analyses of enterovirus 71 strains from fatal and non-fatal cases of the hand, foot and mouth disease outbreak in Singapore (2000). Microbiol Immunol 2002; 46: 801-08.

83 Ooi MH, Wong SC, Podin Y, et al. Human enterovirus 71 disease in Sarawak, Malaysia: a prospective clinical, virological, and molecular epidemiological study. Clin Infect Dis 2007; 44: 646-56.

84 Ooi MH, Wong SC, Clear D, et al. Adenovirus type 21-associated acute flaccid paralysis during an outbreak of hand-foot-and-mouth disease in Sarawak, Malaysia. Clin Infect Dis 2003; 36: 550-59.

85 Chang LY, Tsao KC, Hsia SH, et al. Transmission and clinical features of enterovirus 71 infections in household contacts in Taiwan. JAMA 2004; 291: 222-27.

86 Chang LY, Chang IS, Chen WJ, et al. HLA-A33 is associated with susceptibility to enterovirus 71 infection. Pediatrics 2008; 122: 1271-76.

87 Yang KD, Yang MY, Li CC, et al. Altered cellular but not humoral reactions in children with complicated enterovirus 71 infections in Taiwan. J Infect Dis 2001; 183: 850-56.

88 Chung P, Huang Y, Chang L, Lin T, Ning H. Duration of enterovirus shedding in stool. J Microbiol Immunol Infect 2001; 34: 167-70.

89 Chen CS, Yao YC, Lin SC, et al. Retrograde axonal transport: a major transmission route of enterovirus 71 in mice. J Virol 2007; 81: 8996-9003.

90 Wong KT, Munisamy B, Ong KC, et al. The distribution of inflammation and virus in human enterovirus 71 encephalomyelitis suggests possible viral spread by neural pathways. J Neuropathol Exp Neurol 2008; 67: 162-69.

91 Ong KC, Badmanathan M, Devi S, Leong KL, Cardosa MJ, Wong KT. Pathologic characterization of a murine model of human enterovirus 71 encephalomyelitis. J Neuropathol Exp Neurol 2008; 67: $532-42$.

92 Shieh WJ, Jung SM, Hsueh C, et al. Pathologic studies of fatal cases in outbreak of hand, foot, and mouth disease, Taiwan. Emerg Infect Dis 2001; 7: 146-48.

93 Hsueh C, Jung SM, Shih SR, et al. Acute encephalomyelitis during an outbreak of enterovirus type 71 infection in Taiwan: report of an autopsy case with pathologic, immunofluorescence, and molecular studies. Mod Pathol 2000; 13: 1200-05.

94 Shen WC, Chiu HH, Chow KC, Tsai CH. MR imaging findings of enteroviral encephalomyelitis: an outbreak in Taiwan. Am J Neuroradiol 1999; 20: 1889-95.

95 German AC, Myint KS, Mai NT, et al. A preliminary neuropathological study of Japanese encephalitis in humans and a mouse model. Trans R Soc Trop Med Hyg 2006; 100: 1135-45.

96 Hoff JT, Nishimura M, Garcia-Uria J, Miranda S. Experimental neurogenic pulmonary edema. Part 1 : The role of systemic hypertension. J Neurosurg 1981; 54: 627-31.

97 Baker AB. Poliomyelitis. A study of pulmonary edema. Neurology 1957; 7: 743-51.

98 Chang LY, Lin TY, Hsu KH, et al. Clinical features and risk factors of pulmonary oedema after enterovirus-71-related hand, foot, and mouth disease. Lancet 1999; 354: 1682-86.

99 Lin TY, Chang LY, Hsia SH, et al. The 1998 enterovirus 71 outbreak in Taiwan: pathogenesis and management. Clin Infect Dis 2002; 34 (suppl 2): S52-57.

100 Wu JM, Wang JN, Tsai YC, et al. Cardiopulmonary manifestations of fulminant enterovirus 71 infection. Pediatrics 2002; 109: e26.

$101 \mathrm{Fu}$ YC, Chi CS, Chiu YT, et al. Cardiac complications of enterovirus rhombencephalitis. Arch Dis Child 2004; 89: 368-73.

102 Huang YF, Chiu PC, Chen CC, et al. Cardiac troponin I: a reliable marker and early myocardial involvement with meningoencephalitis after fatal enterovirus-71 infection. $J$ Infect 2003; 46: 238-43.

$103 \mathrm{Fu}$ YC, Chi CS, Jan SL, et al. Pulmonary edema of enterovirus 71 encephalomyelitis is associated with left ventricular failure: implications for treatment. Pediatr Pulmonol 2003; 35: 263-68.

104 Fu YC, Chi CS, Lin NN, et al. Comparison of heart failure in children with enterovirus 71 rhombencephalitis and cats with norepinephrine cardiotoxicity. Pediatr Cardiol 2006; 27: 577-84.

105 Lin TY, Hsia SH, Huang YC, Wu CT, Chang LY. Proinflammatory cytokine reactions in enterovirus 71 infections of the central nervous system. Clin Infect Dis 2003; 36: 269-74.
106 Lin TY, Chang LY, Huang YC, Hsu KH, Chiu CH, Yang KD. Different proinflammatory reactions in fatal and non-fatal enterovirus 71 infections: implications for early recognition and therapy. Acta Paediatr 2002; 91: 632-35.

107 Wang SM, Lei HY, Huang KJ, et al. Pathogenesis of enterovirus 71 brainstem encephalitis in pediatric patients: roles of cytokines and cellular immune activation in patients with pulmonary edema. $J$ Infect Dis 2003; 188: 564-70.

108 Wang SM, Lei HY, Yu CK, Wang JR, Su IJ, Liu CC. Acute chemokine response in the blood and cerebrospinal fluid of children with enterovirus 71-associated brainstem encephalitis. J Infect Dis 2008; 198: 1002-06.

109 Ooi MH, Wong S, Mohan A, et al. Identification and validation of clinical predictors for the risk of neurological involvement in children with hand, foot, and mouth disease in Sarawak. BMC Infect Dis 2009; 9: 3.

110 Chang LY, Hsia SH, Wu CT, et al. Outcome of enterovirus 71 infections with or without stage-based management: 1998 to 2002 . Pediatr Infect Dis J 2004; 23: 327-31.

111 Wang S, Lei H, Huang M, et al. Modulation of cytokine production by intravenous immunoglobulin in patients with enterovirus 71-associated brainstem encephalitis. J Clin Virol 2006; 37: 47-52.

112 Chen YC, Yu CK, Wang YF, Liu CC, Su IJ, Lei HY. A murine oral enterovirus 71 infection model with central nervous system involvement. J Gen Virol 2004; 85: 69-77.

113 Arita M, Shimizu H, Nagata N, et al. Temperature-sensitive mutants of enterovirus 71 show attenuation in cynomolgus monkeys. J Gen Virol 2005; 86: 1391-401.

114 Wang YF, Chou CT, Lei HY, et al. A mouse-adapted enterovirus 71 strain causes neurological disease in mice after oral infection. J Virol 2004; 78: 7916-24.

115 Ang LW, Koh BK, Chan KP, Chua LT, James L, Goh KT. Epidemiology and control of hand, foot and mouth disease in Singapore, 2001-2007. Ann Acad Med Singapore 2009; 38: 106-12.

116 Forum on Hand Foot and Mouth Disease (HFMD) in Asia-Pacific Region: Epidemiological, Laboratory, Clinical, and Public Health aspects. Singapore: Regional Emerging Disease Intervention Center and The Ministry of Health Singapore; 2009.

117 Wu CN, Lin YC, Fann C, Liao NS, Shih SR, Ho MS. Protection against lethal enterovirus 71 infection in newborn mice by passive immunization with subunit VP1 vaccines and inactivated virus. Vaccine 2001; 20: 895-904.

118 Xu J, Qian Y, Wang S, et al. EV71: An emerging infectious disease vaccine target in the Far East? Vaccine 2010; 28: 3516-21.

119 Lee MS, Chang LY. Development of enterovirus 71 vaccines. Expert Rev Vaccines 2010 9: 149-56.

120 Liu CC, Lian WC, Butler M, Wu SC. High immunogenic enterovirus 71 strain and its production using serum-free microcarrier Vero cell culture. Vaccine 2007; 25: 19-24.

121 Chung YC, Ho MS, Wu JC, et al. Immunization with virus-like particles of enterovirus 71 elicits potent immune responses and protects mice against lethal challenge. Vaccine 2008; 26: 1855-62.

122 Tung WS, Bakar SA, Sekawi Z, Rosli R. DNA vaccine constructs against enterovirus 71 elicit immune response in mice. Genet Vaccines Ther 2007; 5: 6.

123 Chiu $\mathrm{CH}$, Chu C, He CC, Lin TY. Protection of neonatal mice from lethal enterovirus 71 infection by maternal immunization with attenuated Salmonella enterica serovar Typhimurium expressing VP1 of enterovirus 71. Microbes Infect 2006; 8: 1671-78.

124 Chen HF, Chang MH, Chiang BL, Jeng ST. Oral immunization of mice using transgenic tomato fruit expressing VP1 protein from enterovirus 71. Vaccine 2006; 24: 2944-51.

125 Foo DG, Alonso S, Phoon MC, Ramachandran NP, Chow VT, Poh CL. Identification of neutralizing linear epitopes from the VP1 capsid protein of Enterovirus 71 using synthetic peptides. Virus Res 2007; 125: 61-68.

126 Arita M, Nagata N, Iwata N, et al. An attenuated strain of enterovirus 71 belonging to genotype A showed a broad spectrum of antigenicity with attenuated neurovirulence in cynomolgus monkeys. J Virol 2007; 81: 9386-95.

127 Solomon T. Flavivirus encephalitis. N Engl J Med 2004; 351: 370-78. 